\title{
DOES THE DEGREE OF CYANOSIS AFFECT MYOCARDIAL ADENOSINE TRIPHOSPHATE LEVELS AND FUNCTION IN CHILDREN UNDERGOING SURGICAL PROCEDURES FOR CONGENITAL HEART DISEASE?
}

Hani K. Najm, MD, MSc ${ }^{\mathrm{a}, \mathrm{c}}$

W. Jack Wallen, MSc ${ }^{\mathrm{d}}$

Michael P. Belanger, AALAS ${ }^{\mathrm{a}, \mathrm{d}}$

William G. Williams MD

John G. Coles, MD ${ }^{\mathrm{a}, \mathrm{c}}$

Glen S. Van Arsdell, MD

Michael D. Black, MD

Christine Boutin, MD ${ }^{\mathrm{b}}$

Carin Wittnich, DVM, MSc ${ }^{\mathrm{a}, \mathrm{c}, \mathrm{d}}$
Objective: The outcome of children with cyanosis after cardiac surgical procedures is inferior to that of children who are acyanotic. Animal studies indicated detrimental effects of chronic hypoxia on myocardial metabolism and function. We studied whether the presence or the degree of cyanosis adversely affected myocardial adenosine triphosphate, ventricular function, and clinical outcome in children. Methods: Forty-eight children who underwent repair of tetralogy of Fallot were divided according to their preoperative saturation: group I, 90\% to $100 \%$ ( $n=14$ patients); group II, $80 \%$ to $89 \%$ ( $n=16$ patients); and group III, $65 \%$ to $79 \%(n=18$ patients $)$. Adenosine triphosphate was measured from right ventricular biopsy specimens taken before ischemia, at 15 minutes of ischemia, at end-ischemia, and at 15 minutes of reperfusion. Ejection fraction was measured by echocardiography. Results: Even before surgical ischemia, compared with groups I and II, group III had lower preoperative ejection fraction $(59 \% \pm 2.9 \%$ vs $67 \%$ $\pm 1.7 \%$ and $68 \% \pm 1.0 \% ; P<.01)$ and lower preischemic adenosine triphosphate levels $(15.1 \pm 2.1$ vs $19.1 \pm 1.9$ and $21.4 \pm 1.5 \mu \mathrm{mol} / \mathrm{g} \mathrm{dry}$ weight; $P<.01)$. After 15 minutes of ischemia, group III had lower adenosine triphosphate levels $(11.2 \pm 1.8$ vs $14.77 \pm 2.3$ and $17.6 \pm 3.1$ $\mu \mathrm{mol} / \mathrm{g}$ dry weight; $\boldsymbol{P}<$.01). With reperfusion, both cyanotic groups lost further adenosine triphosphate compared with partial recovery in the acyanotic group $(-22 \% \pm 3.8 \%,-20 \% \pm 3.1 \%$ vs $+18 \% \pm 1.8 \% ; P<.01)$. Children in group III had a more complicated postoperative course as evidenced by longer ventilatory support $(85 \pm 25$ hours vs $31 \pm 15$ and $40 \pm 21$ hours; $P=.07)$, inotropic support (86 \pm 23 hours vs $38 \pm 12$ and $36 \pm 4$ hours; $P<.01)$, and intensive care unit stay $(160 \pm 35$ hours vs 60 \pm 10 and $82 \pm 18$ hours; $P=.02)$. Conclusions: The degree of cyanosis adversely affects myocardial adenosine triphosphate, function, and clinical outcome of children who undergo cardiac operation. Children with cyanosis should be identified as a higher risk group that could be targeted for supportive interventions. (J Thorac Cardiovasc Surg 2000;119:515-24)
$\mathrm{D}$ espite the advances in cardiac surgical procedures there are still subgroups of children who are identified to be at a higher risk of perioperative morbidity and

From the Division of Cardiovascular Surgery, Department of Surgery, ${ }^{\mathrm{a}}$ and the Division of Pediatric Cardiology, Department of Pediatrics, ${ }^{b}$ the Hospital for Sick Children, and the Institute of Medical Sciences, ${ }^{\mathrm{c}}$ and the Department of Physiology, University of Toronto, Toronto, Ontario, Canada.

Funded by a grant from the Heart \& Stroke Foundation of Ontario, No. T4181.

Read at the Seventy-ninth Annual Meeting of The American Association for Thoracic Surgery, New Orleans, La, April 18-21, 1999. death. The presence of severe hypoxia has been identified to be deleterious to the cardiac metabolic profile in animals. ${ }^{1}$ In human beings the effects of cyanosis on

Received for publication April 27, 1999; revisions requested July 7, 1999; revisions received Oct 18, 1999; accepted for publication Oct 28, 1999.

Address for reprints: Carin Wittnich, DVM, Associate Professor of Surgery, Rm 7256, Medical Science Building, 1 King's College Circle, University of Toronto, Toronto, Canada, M5S 1A8 (Email: c.wittnich@utoronto.ca).

Copyright @ 2000 by Mosby, Inc.

$0022-5223 / 2000 \$ 12.00+0 \quad \mathbf{1 2 / 6 / 1 0 4 3 3 9}$

doi:10.1067/mtc.2000.104339 


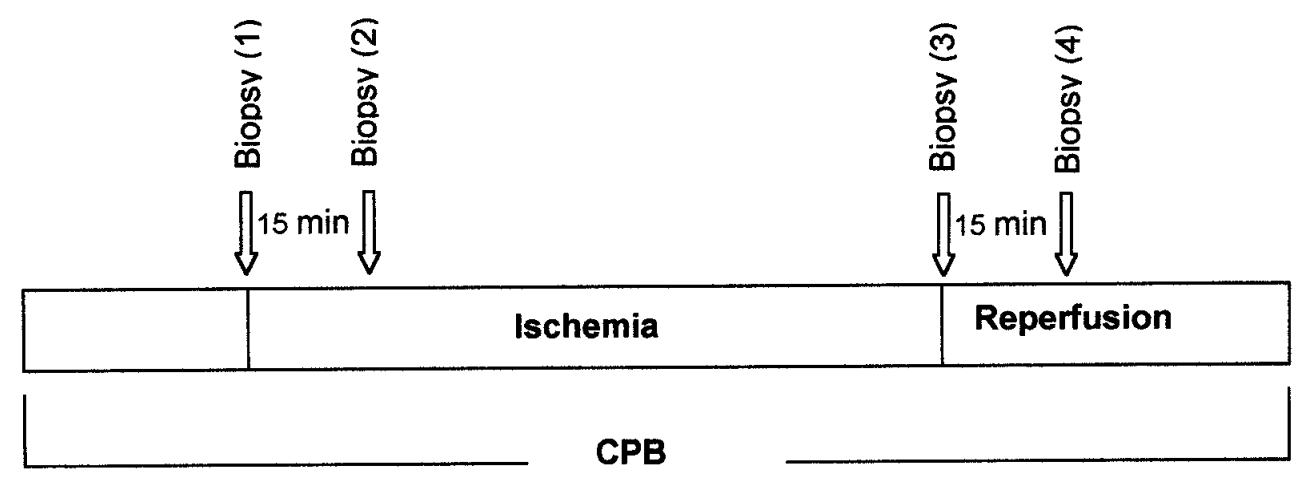

Fig 1. Myocardial biopsy protocol. Biopsy (1), baseline or control; Biopsy (2), 15 minutes of ischemia; Biopsy (3), end-ischemia; and Biopsy (4), 15 minutes of reperfusion.

myocardial metabolism have not been well established. If in children, as seen in animals, chronic exposure to low oxygen tension $\left(\mathrm{PO}_{2}\right)$ is deleterious to myocardial function, ${ }^{2}$ then the identification of children at higher risk who are undergoing cardiac surgical procedures allows for better allocation of hospital resources, improved outcome, and substantially reduced hospital costs. ${ }^{3}$

The question remains whether the degree of cyanosis unfavorably changes the myocardial metabolism of children who undergo cardiac surgical procedures even before surgically induced ischemia and whether the inevitable myocardial ischemia and reperfusion, occurring during open cardiac operations, would further increase this derangement.

This prospective observational study was designed to examine the effects of the degree of cyanosis on myocardial adenosine triphosphate levels (ATP) at baseline, at ischemia, and at reperfusion. In addition the association between the metabolic derangement, ventricular function, and clinical outcome were examined.

\section{Subjects and methods}

Patients. This study was approved by the medical ethics committee at the Hospital for Sick Children, Toronto, Canada. A parental informed consent was obtained in all children who were recruited in this study. Forty-eight consecutive children with tetralogy of Fallot (TOF) were enrolled between January 1997 and April 1998. Children with diabetes, children born to a diabetic mother undergoing repair in the neonatal period, or children who were undergoing emergency operations were excluded from this study. The exclusion was based on the possibility that altered carbohydrate metabolism present in patients with diabetes may influence glycolytic pathways and therefore may affect myocardial energy stores (eg, ATP).

Preoperative details. The overall median age was 378 days (25th and 75th percentile: range, 76-819 days). Twenty- five children were male. The mean preoperative weight was $9.3 \pm 4.1 \mathrm{~kg}$, and the preoperative hemoglobin level was $136.3 \pm 19 \mathrm{~g} / \mathrm{L}$. None of the children had a preoperative palliative procedure, except 1 child with pulmonary atresia who underwent a right ventricular outflow tract reconstruction before repair.

Operative details. All children underwent the usual cardiac anesthesia. Standard cardiopulmonary bypass was initiated, with aortic and bicaval cannulation initially at normothermia, after which the child's body was cooled to moderate hypothermia during the operation. After stabilization, an aortic crossclamp was applied, and $30 \mathrm{~mL} / \mathrm{kg}$ cold blood cardioplegic solution was delivered to the heart by way of the aortic root to effect cardiac arrest, which was maintained by subsequent doses of cardioplegic solution every 20 minutes. After the right atrium was opened and the anatomy was verified, the ventricular septal defect was closed with a Dacron patch followed by atrial septal defect closure. The right ventricular outflow tract was enlarged by muscle resection alone in 21 patients (44\%) and by muscle resection with a transannular patch in 27 patients $(56 \%)$. The heart was then closed, and the child was brought to normothermia and weaned from cardiopulmonary bypass. Modified ultrafiltration was performed in children with a body weight of less than $15 \mathrm{~kg}$.

Myocardial metabolic assessment. To determine changes in myocardial metabolism, right ventricular myocardial biopsy specimens were taken as detailed in Fig 1. Biopsy specimens were taken at 4 intervals: baseline or control (immediately after initial cardioplegia), at 15 minutes of ischemia, at end-ischemia, and at 15 minutes of reperfusion. The concentration of ATP (micromoles per gram of dry weight) was determined by high-performance liquid chromatography with the method of Smolenski and colleagues. ${ }^{4}$

Assessment of myocardial function. All children underwent a preoperative transthoracic echocardiogram within 1 week before the operation to assess ventricular function. A transesophageal echocardiogram was performed in the operating room after the intracardiac repair and the patient was weaned from cardiopulmonary bypass (CPB). A third 
Table I. Clinical characteristics of all children classified by degree of cyanosis

\begin{tabular}{|c|c|c|c|c|}
\hline \multirow[b]{2}{*}{ Characteristics } & \multicolumn{3}{|c|}{ Group } & \multirow[b]{2}{*}{$\mathrm{P}$ value } \\
\hline & $I$ & $I I$ & III & \\
\hline Patients (n) & 14 & 16 & 18 & \\
\hline \multicolumn{5}{|l|}{ Preoperative } \\
\hline Median age $(d)$ & 385 & 366 & 299 & \\
\hline 1st and 3rd quartiles (d) & $215-819$ & $265-464$ & $76-660$ & \\
\hline Age range $(\mathrm{d})$ & $56-1725$ & 88-1906 & $1-3308$ & \\
\hline Weight $(\mathrm{kg})$ & $10 \pm 3.9$ & $8.6 \pm 3.5$ & $9.3 \pm 6.2$ & .7 \\
\hline $\operatorname{BSA}\left(\mathrm{m}^{2}\right)$ & $0.46 \pm 0.09$ & $0.42 \pm 0.10$ & $0.42 \pm 0.17$ & .6 \\
\hline Saturation (\%) & $94.7 \pm 2.5$ & $85.1 \pm 2.8^{*}$ & $75.8 \pm 2.7^{* \dagger}$ & $<.01$ \\
\hline Hemoglobin $(\mathrm{g} / \mathrm{L})$ & $124 \pm 20$ & $126 \pm 13$ & $146 \pm 21^{* \dagger}$ & $<.01$ \\
\hline Hematocrit $(\%)$ & $36 \pm 6.1$ & $37 \pm 4.4$ & $42 \pm 5.8^{* \dagger}$ & $<.01$ \\
\hline \multicolumn{5}{|l|}{ Operative } \\
\hline Lowest body temperature $\left({ }^{\circ} \mathrm{C}\right)$ & $29.7 \pm 3.1$ & $28.9 \pm 2.5$ & $27.8 \pm 3.5$ & .2 \\
\hline Ischemic time (min) & $59 \pm 11$ & $62 \pm 12$ & $61 \pm 27$ & .9 \\
\hline Total CPB time (min) & $122 \pm 30$ & $127 \pm 50$ & $165 \pm 52^{* \dagger}$ & $<.01$ \\
\hline Prebypass $\mathrm{PaO}_{2}^{\dagger}(\mathrm{mm} \mathrm{Hg})$ & $134 \pm 68$ & $142 \pm 86$ & $79 \pm 37^{\dagger}$ & .02 \\
\hline Transannular patch $(\%)$ & 21 & 38 & 44 & .4 \\
\hline \multicolumn{5}{|l|}{$\mathrm{PaO}_{2}$ during bypass $(\mathrm{mm} \mathrm{Hg})$} \\
\hline Onset of ischemia & $197 \pm 98$ & $177 \pm 80$ & $182 \pm 74$ & .8 \\
\hline End-ischemia & $189 \pm 55$ & $173 \pm 54$ & $177 \pm 54$ & .7 \\
\hline Reperfusion & $192 \pm 38$ & $184 \pm 67$ & $177 \pm 46$ & .7 \\
\hline
\end{tabular}

$\mathrm{BSA}$, Body surface area; $\mathrm{PaO}_{2}$, partial pressure of arterial oxygen.

*Statistical difference compared with group I.

'Statistical difference compared with group II.

Prebypass $\mathrm{PaO}_{2}$; the child is anesthetized and has undergone ventilation.

transthoracic echocardiogram was performed within postoperative week 1 to further evaluate ventricular function.

To standardize the preoperative, intraoperative, and postoperative assessment of these children, the echocardiographic studies were evaluated by one person and included an assessment of the systolic function by ejection fraction $(\mathrm{EF}) .^{5}$

Assessment of outcome. Because of the ever-decreasing mortality rate of repair of TOF, which is currently less than $2 \%$ at the Hospital for Sick Children in Toronto (unpublished data) and in other centers, ${ }^{6}$ other clinical outcome variables were examined. These included the length of inotropic and ventilatory support and the length of intensive care unit (ICU) and hospital stay. In addition, the prevalence of in-hospital complications was compared in the different groups.

Data acquisition. This was a prospective study design. All perioperative clinical and biochemical data were collected in a blinded fashion. Preoperative, operative, and postoperative variables were collected prospectively.

Data analysis. To identify the effects of cyanosis on the outcome of interest, children were allocated into three subgroups, depending on their aortic oxygen saturation as determined by the preoperative cardiac catheterization: acyanotic, $90 \%$ to $100 \%$; mildly cyanotic, $80 \%$ to $89 \%$; moderately to severely cyanotic, $65 \%$ to $79 \%$. These divisions were created because an arterial oxygen saturation above $90 \%$ would be considered acyanotic or normal, whereas saturations below $80 \%$ are clearly significant cyanosis. Saturations between $80 \%$ and $89 \%$ were grouped together as the intermediate group. This facilitated the presentation and analysis of the clinical outcomes.

Statistical methods. Data are expressed as mean \pm standard error of mean except if descriptive, where standard deviation is used. Differences in continuous variables between the different groups were assessed with analysis of variance and the Tukey post hoc test was performed for significant analyses of variance. Linear regression was used to determine the correlation between saturation and ATP, and multiple regression was used to delineate the relative contribution of different variables. Difference in proportions was tested with the $\chi^{2}$ test.

\section{Results}

Forty-eight children were recruited for this study and allocated to the three previously described subgroups on the basis of their preoperative saturation. Table I details the characteristics of these subgroups. As expected, preoperative saturation, hemoglobin, and hematocrit were statistically different between the groups. Although the total $\mathrm{CPB}$ time was longer in group III, the ischemic time was comparable. Although all children underwent ventilation, the pre-CPB $\mathrm{PO}_{2}$ was lower in group III.

ATP. The level of myocardial ATP at baseline was significantly lower in groups II and III as compared with group I $(P<.01 ;$ Fig $2, A)$. There was a graded 

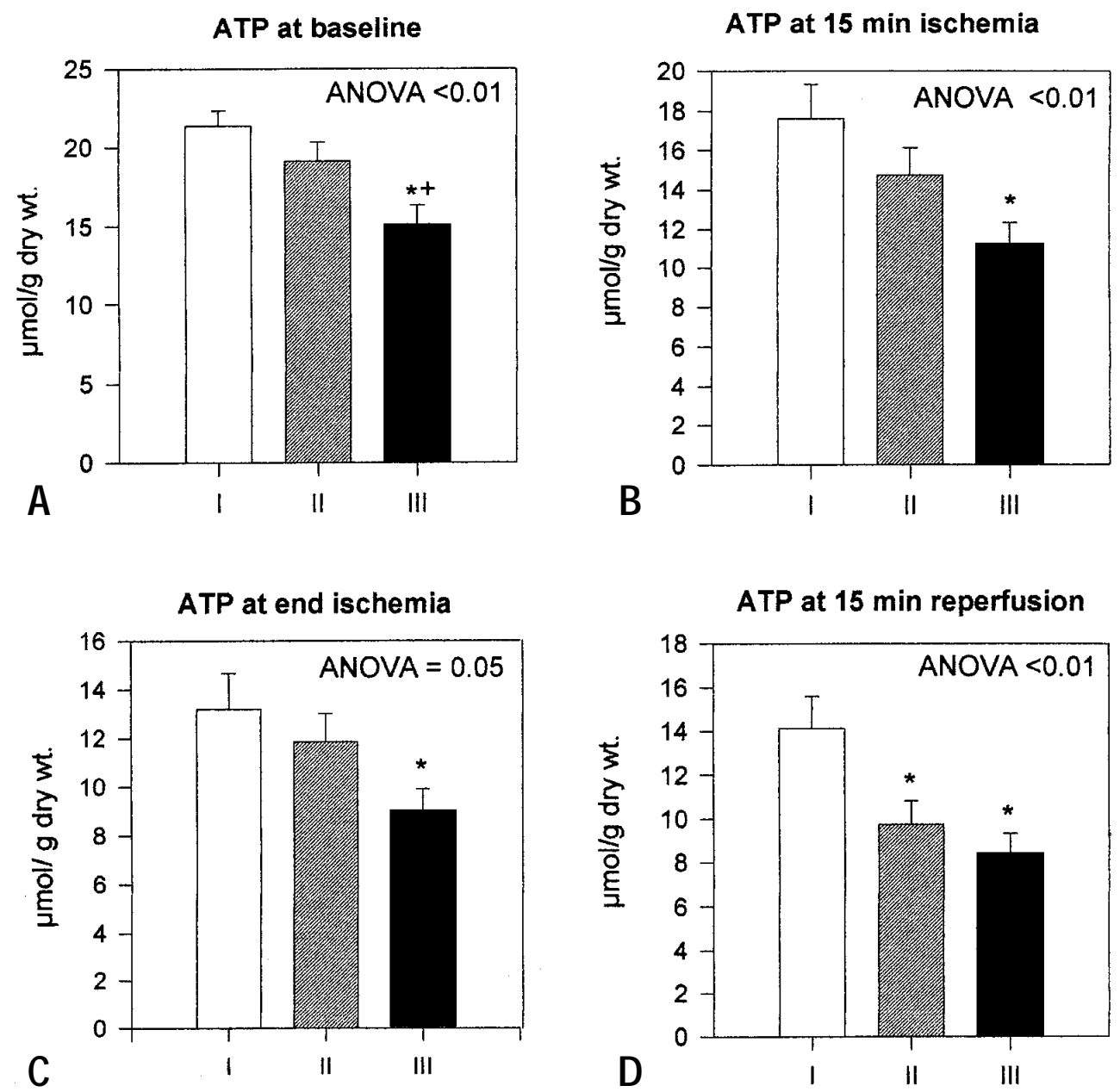

Fig 2. Myocardial ATP levels at different time intervals. (A) Baseline, (B) 15 minutes of ischemia, (C) endischemia, and (D) 15 minutes of reperfusion in groups I, II, and III. *Significance versus group I. ${ }^{\dagger}$ Significance versus group II.

response to the degree of cyanosis with group II, which had a mild effect on the baseline ATP level, and a moderate response in group III. There was a significant positive correlation between the preoperative saturation level and the baseline ATP level $(r=0.65 ; P<.01)$.

At 15 minutes of ischemia, group III continued to have depressed ATP levels as compared with the other groups $(P<.01 ;$ Fig $2, B)$. The graded response still existed among the groups. There was a significant positive correlation between the preoperative saturation and the 15-minute ischemia levels of ATP $(r=0.47 ; P$ $<.01)$.

To determine the percentage loss of ATP during the initial ischemia, the difference between baseline and 15 minutes was calculated and expressed as a percentage of the baseline value. All three groups had lost a signif- icant percentage $(P<.01)$ of their initial ATP level by 15 minutes of ischemia (group I, $18 \%$; group II, 28\%; group III, 35\%). Again there was a graded response to cyanosis with a progressive increase in the loss of baseline ATP with decreasing saturation. The difference between the groups at 15 minutes did not reach statistical significance when analysis of variance was used $(P=.29)$. However, by linear regression (percent change treated as a continuous variable), there was a significant negative correlation between preoperative saturation and the percentage loss of ATP from baseline $(r=0.30 ; P=.04)$.

ATP at end-ischemia was statistically lower in group III compared with the other two groups $(P=.05$; Fig 2 , $C)$. By linear regression there was a statistically significant positive correlation between saturation and ATP 
level at end-ischemia $(r=0.33 ; P=.02)$. After 15 minutes of reperfusion the ATP level in both cyanotic groups (groups II and III) was lower than the acyanotic group (group I; $P<.01 ;$ Fig $2, D$ ). In addition there was a positive correlation between preoperative saturation level and the ATP level after 15 minutes of reperfusion $(r=0.48 ; P<.01)$.

To determine whether there was a net recovery or loss of ATP after 15 minutes of reperfusion, the difference between end-ischemia and the 15-minute reperfusion levels was calculated and expressed as the percentage of either further loss or recovery of ATP. Both cyanotic groups (groups II and III) showed further losses of ATP (20\% and $23 \%$, respectively) with 15 minutes of reperfusion as compared with a net recovery of $18 \%$ in the acyanotic group $(P<.01$; Fig 3$)$.

With the use of multivariate analysis (Tables II and III) at baseline, preoperative saturation continued to be highly predictive of ATP levels. By 15 minutes of ischemia and at end-ischemia, this association was lost. ATP levels at end-ischemia predicted the values after 15 minutes of reperfusion.

Ventricular function differences. Preoperative echocardiography showed a lower EF in group III $(59 \% \pm 2.9 \%)$ when compared with both the other groups $(67 \% \pm 1.7 \%$ and $68 \% \pm 1.0 \%$ for groups I and II, respectively; $P<.01)$. The intraoperative echocardiogram showed both cyanotic groups had lower EFs $(57 \% \pm 3.6 \%$ for group II and $63 \% \pm 1.8 \%$ for group III) than the acyanotic group $(68 \% \pm 0.9 \% ; P=.02)$. Postoperative EFs had a similar pattern (group I, 67\% $\pm 3.1 \%$; group II, $63 \% \pm 0.8 \%$; and group III, $60 \% \pm$ $1.0 \% ; P=.01)$ with worse ventricular function in group III (Fig 4).

Clinical outcome. There were no deaths in the series of children enrolled in this study. The postoperative oxygen saturation was above $90 \%$ in all children. Cyanotic children in group III experienced longer inotropic and ventilatory support when compared with children in groups I and II $(P<.01$ and .07 , respectively; Fig 5, $A$ and $B$ ). A similar pattern was seen with ICU stay, which was prolonged in the most severely cyanotic group (group III; $P=.02$ ). Hospital stay was longer in the cyanotic group but did not reach statistical significance $(P=.3)$. In the multivariate analysis, preoperative EF (coefficient, 0.403; standard error (SE), $0.160 ; P=.01$ ) and total pump time (coefficient, 0.823; $\mathrm{SE}, 0.345 ; P=.02$ ) were predictors of longer postoperative inotropic support, although baseline ATP predicted length of ICU and hospital stay (coefficient, 0.695; SE, 0.311; $P=.001$; and coefficient, 0.704; SE, 0.326; $P=.04$, respectively).
$\%$ Recovery of ATP at $15 \mathrm{~min}$ reperfusion

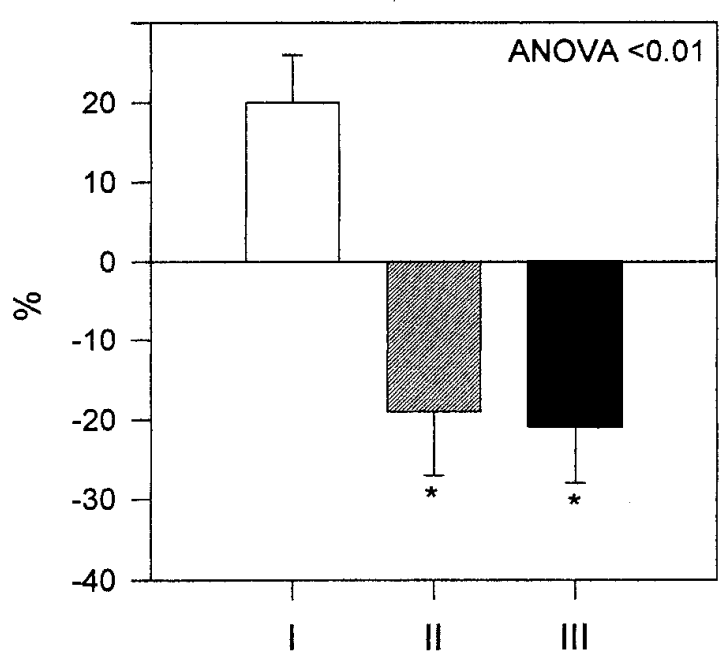

Fig 3. Percent recovery of ATP from end-ischemia to $15 \mathrm{~min}$ utes of reperfusion. *Significance versus group I.

The prevalence of complications (defined as arrhythmia, infections, renal failure, low cardiac output syndrome, and other) in group I was $21 \%$ as compared with $43 \%$ for group II and $50 \%$ for group III $(P=.26)$. Table IV lists the details of complications.

\section{Discussion}

This study demonstrated the deleterious effects of cyanosis on preoperative ventricular function and baseline ATP levels and its adverse effects on ATP levels during early ischemia and reperfusion. In addition, this study demonstrated an association of cyanosis with worse postoperative ventricular function and a more complex postoperative hospital course.

Progress in pediatric cardiac surgery in the past couple of decades, in general, has made a tremendous impact on outcome. The mortality rate of simple and complex defect repair has decreased, ${ }^{7,8}$ and previously nonoperable defects such as hypoplastic left heart syndrome have become operable. ${ }^{9,10}$ There are still some subsets of children who are undergoing cardiac surgery who would have either a prolonged or complicated postoperative course. Despite improvements in mortality rates, attention should be directed to specific "highrisk" groups, such as children with congestive heart failure or, as seen in this study, children with severe cyanosis.

The high-energy phosphate bond of ATP serves as the main energy source for myocardial contraction. ${ }^{11}$ Levels of ATP relate closely to myocardial function before, during, and after periods of ischemia. ${ }^{12}$ 
Table II. Multivariate analysis for ATP (additional variables were added to the model as appropriate)

\begin{tabular}{|c|c|c|c|c|c|c|}
\hline \multirow[b]{2}{*}{ Variable } & \multicolumn{3}{|c|}{ Baseline ATP level } & \multicolumn{3}{|c|}{ Fifteen-minute ischemia ATP level } \\
\hline & Coefficient & $S E$ & $\mathrm{P}$ value & Coefficient & $S E$ & $\mathrm{P}$ value \\
\hline Age & 0.232 & 0.127 & .8 & 0.124 & 0.127 & .3 \\
\hline Preoperative saturation & 0.592 & 0.131 & $<.01$ & 0.240 & 0.160 & .1 \\
\hline Preoperative EF & 0.011 & 0.140 & .1 & 0.027 & 0.135 & .8 \\
\hline Baseline ATP & & & & 0.530 & 0.160 & $<.01$ \\
\hline
\end{tabular}

Table III. Multivariate analysis for ATP (additional variables were added to the model as appropriate)

\begin{tabular}{|c|c|c|c|c|c|c|}
\hline \multirow[b]{2}{*}{ Variable } & \multicolumn{3}{|c|}{ End-ischemia ATP level } & \multicolumn{3}{|c|}{ Fifteen-minute reperfusion ATP } \\
\hline & Coefficient & $S E$ & $\mathrm{P}$ value & Coefficient & $S E$ & $\mathrm{P}$ value \\
\hline Age & 0.017 & 0.148 & .9 & 0.037 & 0.133 & .8 \\
\hline Preoperative saturation & 0.070 & 0.187 & .7 & 0.274 & 0.169 & .1 \\
\hline Preoperative EF & 0.217 & 0.159 & .2 & 0.091 & 0.141 & .5 \\
\hline Baseline ATP & 0.551 & 0.219 & .01 & 0.220 & 0.20 & .3 \\
\hline Fifteen-minute ischemia ATP & 0.116 & 0.205 & .6 & 0.033 & 0.165 & .8 \\
\hline Myocardial ischemic time & 0.106 & 0.150 & .5 & 0.043 & 0.116 & .7 \\
\hline End-ischemia ATP & & & & 0.471 & 0.147 & $<.01$ \\
\hline
\end{tabular}

Likewise interventions that replenish ATP levels after ischemia have been demonstrated to improve myocardial functional recovery after ischemia. ${ }^{13}$ In a canine model, Silverman and colleagues ${ }^{2}$ created a chronic hypoxia model by anastomosing the left atrium to the pulmonary artery. This study showed no baseline adenine nucleotide differences in hearts of cyanotic versus the acyanotic animals. Nevertheless, there was a decrease in right and left ventricular EF at baseline in the cyanotic animals. After 60 minutes of myocardial ischemia, the cyanotic group showed accelerated depletion of high-energy phosphates; and with 60 minutes of reperfusion, these hearts failed to recover the lost ATP. In the current clinical study, in contrast to Silverman and colleagues, the hearts of children with cyanosis clearly had lower ATP levels at baseline together with reduced ventricular function, whereas the findings during ischemia and at reperfusion agree with data of Silverman and colleagues. The conflicting results seen at baseline between the current clinical study and the animal model of Silverman and colleagues may be due to the fact that children with cyanotic congenital heart disease have been cyanotic since birth and have never been exposed to normoxia. There may be a persistence of the hypoxic fetal environment after birth until the day of operation, which may inhibit or delay metabolic maturation of these children. On the other hand, all chronic hypoxia animal models, at the present time, examine the effects of introduction of hypoxia for a certain period of time to a previously normoxic animal.
This animal will have had a period of maturation or adaptation to the higher oxygen environment. The impact of normoxic exposure for a period of time before chronic hypoxia has not, as yet, been clarified; therefore interpretation of animal data ${ }^{14}$ using such models should be done with caution.

Previous studies indicated that an ATP reduction of $30 \%$ to $40 \%$ is certainly compatible with cellular survival in early ischemia and in the postischemic recovery phase, but it does affect cellular function. ${ }^{15}$ It is not until ATP levels are between 2 and $4 \mu \mathrm{mol} / \mathrm{g}$ dry weight that complete metabolic and functional recovery is unlikely. ${ }^{15}$ None of the children in this study experienced a drop of their ATP to this level, which would suggest that metabolic recovery is expected in these children. However, with 15 minutes of reperfusion, the best recovery of ATP level as a percentage of baseline value was in the acyanotic group in which $70 \%$ of the baseline ATP was restored compared with only $47 \%$ to $59 \%$ in the cyanotic groups.

During the reperfusion period after both 1- and 2hour periods of hypothermic cardioplegic arrest, Engelman and colleagues ${ }^{16}$ showed, in mature acyanotic pig hearts, a trend to decreasing ATP content. Other investigators have either confirmed continued depletion of ATP during early reperfusion ${ }^{2,16,17}$ or restoration of ATP levels immediately after reperfusion both in immature ${ }^{18}$ and mature hearts. ${ }^{19}$ In the current study, there was a further loss of ATP from end-ischemia to 15 minutes of reperfusion in hearts of children with 
Table IV. Details of complications

\begin{tabular}{lccc}
\hline Type of complication $(n)$ & $\begin{array}{c}\text { Group I } \\
(n=14)\end{array}$ & $\begin{array}{c}\text { Group II } \\
(n=16)\end{array}$ & $\begin{array}{c}\text { Group III } \\
(n=18)\end{array}$ \\
\hline Arrhythmia & 2 & 4 & 5 \\
Low cardiac output & 0 & 1 & 2 \\
Infection & 1 & 0 & 1 \\
Renal failure & 0 & 0 & 0 \\
Other & 0 & 2 & 1 \\
Total $(\%)$ & $3(21)$ & $7(43)$ & $9(50)$ \\
\hline
\end{tabular}

cyanosis, reaching a further $23 \%$ reduction as compared with an actual recovery (restoration) of $18 \%$ of ATP level with 15 minutes of reperfusion in the hearts of children who were acyanotic. This represents a significant and potentially detrimental response of cyanotic hearts even at reperfusion. Because of inaccessibility to myocardial sampling after the 15 minutes of reperfusion, this study protocol did not follow the metabolic recovery of these hearts after the initial 15 minutes of reperfusion. Del Nido and colleagues ${ }^{20}$ examined adenine nucleotides up to 30 minutes of reperfusion in children with TOF and adults with coronary artery disease. They concluded children had a greater reduction in ATP levels during ischemia and further loss with 30 minutes of reperfusion when compared with adults. This study did not take into account the presence of different pathologic features (TOF and coronary artery disease) or the possible presence of cyanosis in the children with TOF. However, when taken together with the current study, it does allude to the possible detrimental effects of cyanosis in children, which persists during reperfusion.

Clinical outcomes examined among the three groups indicated evidence of prolonged inotropic and ventilatory support and prolonged ICU and hospital stay in children with severe cyanosis. The effect of cyanosis on clinical outcome was clearly evident in group III (saturation, 65\%-79\%), although group II (saturation, 80\%$89 \%$ ) behaved closer to the acyanotic group (saturation, 90\%-100\%). The extended length of inotropic support is an indication of compromised ventricular function. Previous reports have linked the metabolic profile of the myocardium to the function of the ventricle. $^{12}$ Whether the absolute value of ATP has a direct correlation with function is controversial. However, reports have indicated that very low ATP can be detrimental to function. Other reasons for prolonged ICU and hospital stay could relate to the development of complications, which was evident in this study. Most of these complications (68\%) were cardiac related, which also reflects the deranged cardiac performance in chil-
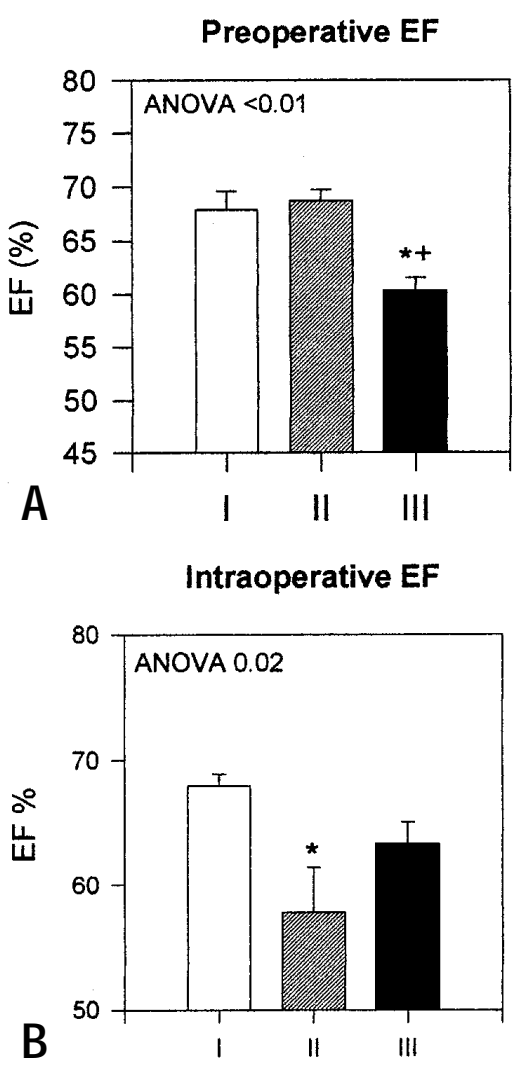

Postoperative EF

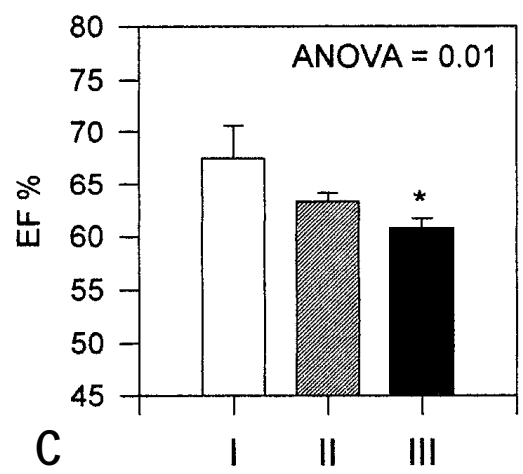

Fig 4. Ventricular EF in (A) preoperative, (B) intraoperative, and (C) postoperative assessment in groups I, II, and III. "Significance versus group I. "Significance versus group II.

dren with cyanosis. Hammon and colleagues ${ }^{12}$ found that most children who lost $40 \%$ of their preischemic ATP either died or had low cardiac output syndrome. These observations reported by Hammon and colleagues, together with those of the current study, highlight the association between underlying metabolic performance and clinical outcome, and this study illustrates that cyanosis has a negative impact on both. 
Duration of inotropic support

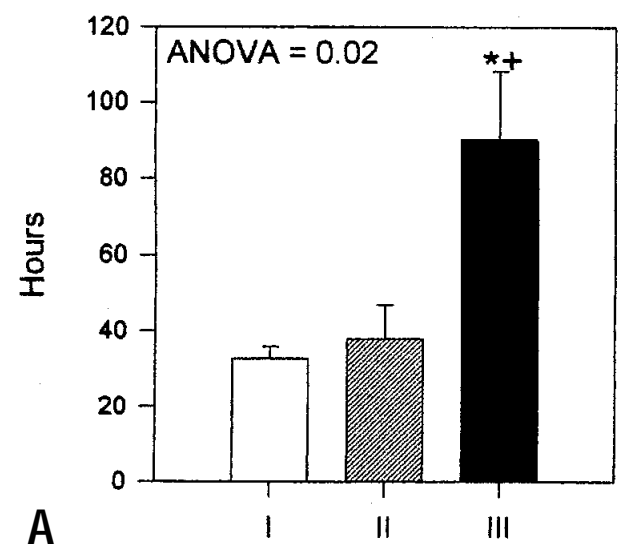

ICU stay

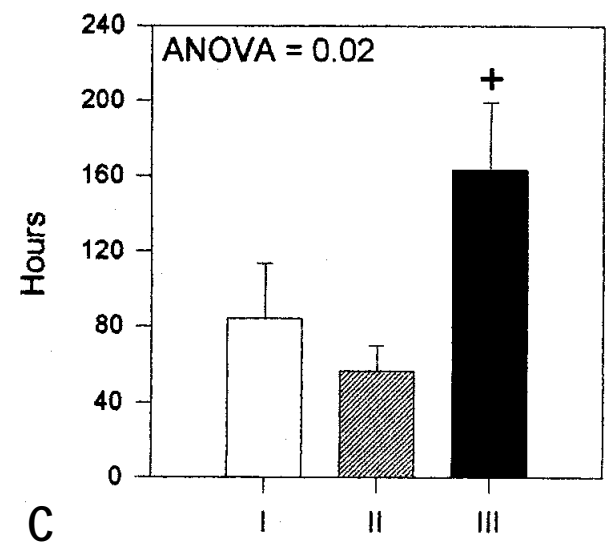

Duration of ventilatory support

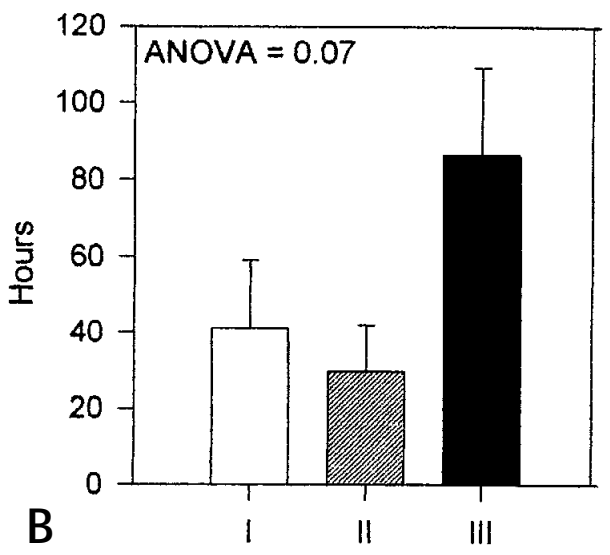

Hospital stay

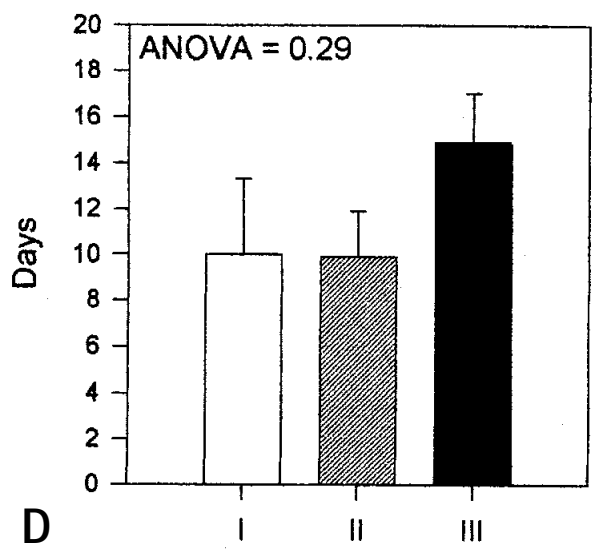

Fig 5. Clinical outcome. (A) Duration of inotropic support, (B) duration of ventilatory support, (C) duration of ICU stay, and (D) duration of hospital stay in groups I, II, and III. *Significance versus group I. `Significance versus group II.

Animal studies have documented deleterious effects of hypoxia on metabolism ${ }^{1}$ and function. ${ }^{2}$ In addition, the graded effect of cyanosis on ATP and outcome suggests that cyanosis itself does play a significant role in these children.

The controversy in the literature regarding the presence or absence of a transannular incision that affects outcome is not yet settled. ${ }^{21,22}$ It is conceivable that children with a worse degree of cyanosis will more likely require a transannular incision during repair compared with children who are acyanotic because of increased right ventricular hypertrophy, which itself may be a marker of complex anatomy. In our children, the prevalence of transannular incisions, though somewhat higher in group III, was not statistically different between the groups.
As with all clinical studies, this study has some limitations, including the fact that some of the variables could not be controlled (such as the degree of ventricular hypertrophy present in these children). It is difficult to accurately and objectively quantify the degree of hypertrophy with 2-dimensional echocardiography. An assessment of ventricular function by echocardiography also has some limitations. It is operator dependent, and there are certain assumptions to the formula used to calculate ventricular volumes. However, it is the most commonly used technique in the evaluation of ventricular function in the perioperative period.

The correlation between right ventricular metabolites and left ventricular function should also be interpreted with caution. It is an association rather than causation. 
Although ideal, left ventricular biopsies impose an additional risk to the child, which is unacceptable.

In conclusion, the results of this study have yielded the following observations: (1) children with severe cyanosis have compromised preoperative ventricular function and low ATP levels before ischemia; (2) ischemia exacerbated the loss of ATP in children who are severely cyanotic; (3) there was further loss of ATP with reperfusion in children with cyanosis; (4) postoperative clinical outcome and ventricular function were worse in children with cyanosis; and (5) the effects of cyanosis on myocardial metabolism was graded in most of the variables measured.

\section{REFERENCES}

1. Wittnich C, Torrance SM. Does the severity of acute hypoxia influence neonatal myocardial metabolism and sensitivity to ischemia? J Mol Cell Cardiol 1994;26:675-82.

2. Silverman NA, Kohler J, Levitsky S, Pavel DG, Fang RB, Feinberg H. Chronic hypoxemia depresses global ventricular function and predisposes to the depletion of high-energy phosphates during cardioplegic arrest: implication for the surgical repair of cyanotic congenital heart defects. Ann Thorac Surg 1984;37:304-8

3. Underleider RM, Bengur AR, Kessenich AL, Liekweg RH, Hart EM, Rice BA, et al. Risk factors for higher cost in congenital heart operations. Ann Thorac Surg 1997;64:44-8.

4. Smolenski RT, Lachno DR, Ledingham SJM, Yacoub MH. Determination of sixteen nucleotides and bases using high-performance liquid chromatography and its application to the study of purine metabolism in hearts for transplantation. J Chromatogr 1990;527:414-20.

5. Snider AR, Serwer GA, Ritter SB, editors. Echocardiography in pediatric heart disease. 2nd ed. Chicago: Mosby; 1995. p. 143.

6. Stellin G, Milanosi O, Tobino M, Michielon G, Biuno R, Morelo GS, et al. Repair of tetralogy of Fallot in the first 6 months of life: transatrial versus transventricular approach. Ann Thorac Surg 1995;60(suppl):S588-91.

7. Cohen DM. Surgical management of congenital heart disease in the 1990s. Am J Dis Child 1992;47:398-403.

8. Cetta F, Feldt RH, O'Leary PW, Mair DD, Warnes CA, Driscoll DJ, et al. Improved early morbidity and mortality after Fontan operation: the Mayo Clinic experience, 1987 to 1992. J Am Coll Cardiol 1996;28:480-6.

9. Norwood WI, Lang P, Hansen D. Physiologic repair of aortic atresia-hypoplastic left heart syndrome. N Engl J Med 1983;308:3-6.

10. Bailey LL, Nehlsen-Cannarella SL, Doroshow RW, Jacobson JG, Martin RD, Allard MW, et al. Cardiac allotransplantation in newborns as therapy for hypoplastic left heart syndrome. N Engl J Med 1986;315:949-51.

11. Katz AM. Contractile proteins of the heart. Physiol Rev 1970; 50:63-158.

12. Hammon JW Jr, Graham TP Jr, Boucek TJ Jr, Parish MD, Merril WH, Bender HW Jr. Myocardial adenosine triphosphate content as a measure of metabolic and functional myocardial protection in children undergoing cardiac operation. Ann Thorac Surg 1987; 44:467-70.

13. Peyton RB, Van Trigt P, Pellom GL, Jones RN, Sink JD, Wechsler
AS. Improved tolerance to ischemia in hypertrophied myocardium by preischemic enhancement of adenosine triphosphate. J Thorac Cardiovasc Surg 1982;84:11-5.

14. Baker JE, Boerboom LE, Olinger GN. Is protection of ischemic neonatal myocardium by cardioplegia species dependent? J Thorac Cardiovasc Surg 1990;99:280-7.

15. Isselhard W. Biochemistry: Index of the functional state of the heart? Br J Anaesth 1988;60:23S-7S.

16. Engelman RM, Rousou JH, Dobbs W, Pels MA, Longo F. The superiority of blood cardioplegia in myocardial preservation. Circulation 1980;62(suppl):61-6.

17. Cunningham JN, Adams PX, Knopp EA, Baumann FH, Snively SL, Gross RI, et al. Preservation of ATP, ultrastructure, and ventricular function after aortic cross clamping and reperfusion. J Thorac Cardiovasc Surg 1979;80:266-76.

18. Julia P, Kofsky ER, Buckberg GD, Young HH, Bugyi HI. Studies of myocardial protection in the immature heart. III. Models of ischemic and hypoxic/ischemic injury in the immature puppy heart. J Thorac Cardiovasc Surg 1991;101:14-22.

19. del Nido PJ, Wilson GJ, Mickle DAG, Bush BG, Rebeyka IM, Klement $\mathrm{P}$, et al. The role of cardioplegic solution buffering in myocardial protection: a biochemical and histological assessment. J Thorac Cardiovasc Surg 1985;89:689-99.

20. del Nido PJ, Mickle DAG, Wilson GJ, Benson LN, Weisel RD, Coles JG, et al. Inadequate myocardial protection with cold cardioplegic arrest during repair of tetralogy of Fallot. J Thorac Cardiovasc Surg 1988;95:223-9.

21. Najm HK, Van Arsdell GS, Watzka S, Hornberger L, Coles JG, Williams WG. Primary repair is superior to initial palliation in children with atrioventricular septal defect and tetralogy of Fallot. J Thorac Cardiovasc Surg 1998;116:905-13.

22. Malm T, Karl TR, Mee RB. Transatrial-transpulmonary repair of atrioventricular septal defect with right ventricular outflow tract obstruction. J Card Surg 1993;8:622-7.

\section{Discussion}

Dr Bradley S. Allen (Oak Lawn, Ill). This is another in an excellent series of clinical studies from the University of Toronto and builds on their previous work in cyanotic infants. Inadequate myocardial protection is still the most common cause of postoperative mortality and morbidity in the pediatric population. Immature hearts were initially thought to be more tolerant to surgical ischemia because only "normal" pediatric hearts were used in early investigative studies. In clinical practice, however, most infant hearts are not "normal" but are subjected to hypoxia or pressure volume overload. This may profoundly alter the heart, making it less tolerant to surgical ischemia and more dependent on the method of myocardial protection. This study, along with their previous work, demonstrates that chronic cyanosis leads to preischemic ATP depletion, as well as reduced tolerance to surgical ischemia. I have several questions.

The average age of patients in this study was approximately $1 \frac{1}{2}$ years old. This is therefore a relatively older group of patients, as many cyanotic infants currently undergo repair at a much earlier age. Did you see the same reduction in ATP levels when you examined your younger patients?

There are numerous preoperative and intraoperative vari- 
ables, such as age, degree of cyanosis, cardiopulmonary bypass time, and use of a transmural patch, to mention only a few. Although it appears that ATP levels correlate with the degree of preoperative cyanosis, did you do a multivariate analysis to ensure that these other variables were not also important in predicting ATP levels?

Aortopulmonary collaterals may be more frequent, especially in severely cyanotic infants. This may lead to rewarming of the heart during cardioplegic arrest, especially if higher bypass temperatures are used. What bypass temperature did you use during myocardial arrest? Was it the same in all groups? Did you notice an increase in aortopulmonary collaterals in any of the groups?

Last, previous studies by your laboratory as well as our laboratory have documented the occurrence of an oxygenderived free radical injury with reoxygenation on cardiopulmonary bypass in cyanotic infants. This results in ATP depletion and depressed myocardial function recovery, even in the absence of surgical ischemia. Furthermore, we demonstrated that this reoxygenation injury could be avoided by using lower initial oxygen levels or a leukodepleting filter. What was the oxygen concentration of your bypass circuit and was it the same in all patients? If it varied, did you notice any change in the ATP levels with different bypass oxygen levels, and do you have any experience with different oxygen levels or leukodepleting filters?

I want to again commend you on an excellent study. It is investigations such as these in the clinical setting that have helped convince us that the pediatric heart is probably more vulnerable to surgical ischemia, and therefore more dependent on the method of myocardial protection.

Dr Najm. With regard to the average age of our patients, it is true that our patients actually have an average age in this cohort of approximately 14 to 18 months. We have substratified the patients in terms of age to see whether there was an age effect or a maturation effect on the adenine nucleotides. Unfortunately, when we looked below 6 months of age we had only 10 patients, leaving only 38 other patients above that age, which would not be a meaningful analysis (10 vs 38 ). Certainly because of this age distribution we may not see a maturational effect. One would presume that most of the maturation occurs in the first month or 2 after birth, and maybe what you see subsequently is not related to maturation.

I am sure that probably everyone in the audience would ask why we divided the saturation into three categories as op- posed to how you use it as a continuous variable. We did that purposely for more than one reason.

The first reason is that linear regression by itself does not detect threshold effect, so we wanted to divide them and see whether there is actually a threshold effect, and indeed we saw that with the reperfusion ATP levels.

The second reason is that we wanted to see how the patients (who were in the middle or the mildly cyanotic group [between $80 \%$ and $90 \%$ ] and who obviously would have fluctuating saturations sometimes, probably going up to $90 \%$ and coming down to $85 \%$ or $80 \%$ ) would behave? It was intriguing that metabolically these patients behave, as we saw, in a graded effect. So they sit actually in between the two groups. But clinically they behave more like patients who are acyanotic. So they had very similar values of inotropic support and length of stay in the hospital like the acyanotic group. For that reason, we kept the saturations divided into three groups so that we could actually see and tease out all these different effects of cyanosis on the outcome of interest.

With respect to the transannular patch and whether we did a multivariate analysis: Because of the absence of death, we are basically stuck with soft outcome variables, which are the length of inotropic support, the ventilation, and all the other parameters. We performed multivariate analysis on them, individually having them as a dependent variable, putting in the equation saturation, age, sex, and the presence of transannular patch. Invariably, we found saturations to predict each one of these variables separately, independent of the other confounding variables.

With respect to your question on oxygen-derived free radical, we are well aware of your outstanding work in this field, and we do believe that there is a place for lowering $\mathrm{PO}_{2}$ on bypass. We have certainly not done that purposely. As you have seen from our $\mathrm{PO}_{2}$ on $\mathrm{CPB}$, we are running the $\mathrm{PO}_{2}$ around $200 \mathrm{~mm} \mathrm{Hg}$, as opposed to many years ago when we used to go up to $400 \mathrm{~mm} \mathrm{Hg}$. Now, we feel slightly uncomfortable at this stage lowering the $\mathrm{Po}_{2}$ further, lower than that, to try and avoid oxygen-derived free radical injury. Certainly work such as what you have done, and the addition of a leukocyte filter, would probably expand to our knowledge in this field where we could actually be comfortable with lowering our $\mathrm{PO}_{2}$ to $100 \mathrm{~mm} \mathrm{Hg}$ or probably even to the preoperative level until the patient's condition is repaired. 